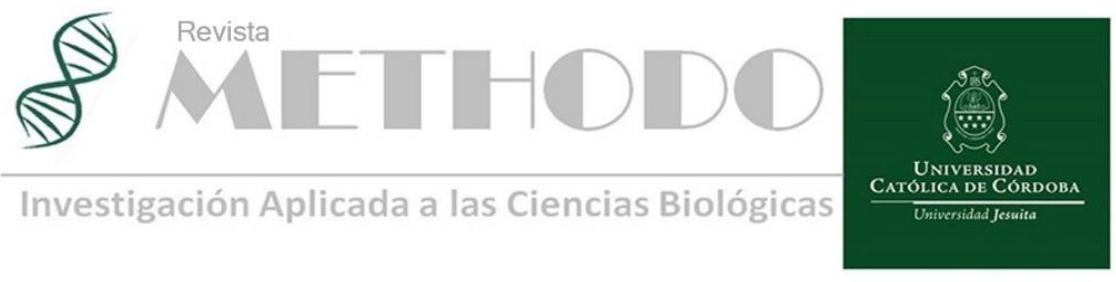

SEMBLANZAS Methodo 2019;4(4):153-155

https://doi.org/10.22529/me.2019.4(4)08

Recibido 8 Sep. 2019 | Aceptado 31 Oct. 2019 |Publicado 27 Dic. 2019

\title{
Prof. Dr. Ángel Segura (1907 - 2005)
}

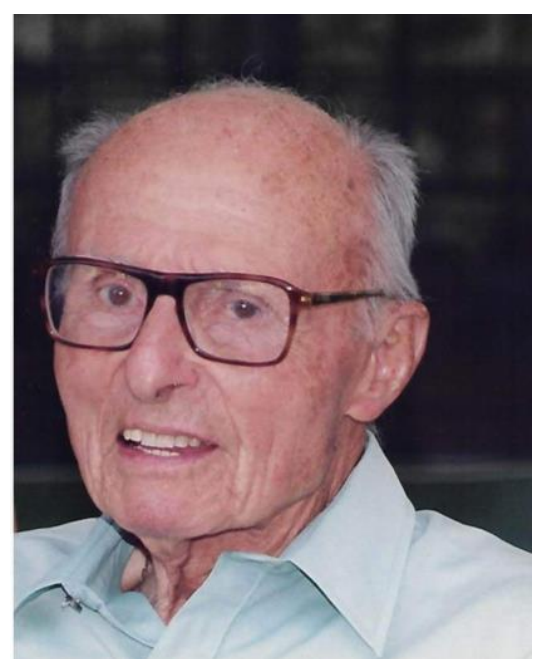

Figura 1. Prof. Dr. Ángel Segura ${ }^{a}$

Como corresponde debo agradecerle al Comité Organizador de las XVI Jornadas de Investigación de la Clínica Universitaria Reina Fabiola por la invitación que recibí para las palabras de cierre de estas Jornadas.

Se me ha encomendado que haga una breve reseña del Prof. Dr. Ángel Segura, (Figura 1) nombre que llevará, a partir de este año 2019, el premio al mejor trabajo científico presentado.

Para mí, es un honor que me hayan designado para esta actividad, y aprovecho, para felicitarlos e instarlos a seguir con estas jornadas por muchos años más, tratando de buscar la excelencia y estimulando la producción científica.

Muchos de ustedes no conocieron a Don Ángel Segura, para ser breve dividiré la presentación en dos partes. La primera sobre su trayectoria académica, que lo hace largamente merecedor de esta distinción, y la segunda contar algunas anécdotas que mostrarán su personalidad, de las cuales yo participé y aprendí.

Primero entonces, les diré por qué concuerdo con el comité organizador en que el premio lleve su nombre y la razón son los méritos científicos y académicos del Dr. Ángel Segura. Nació en 1907. En 1952, fue profesor titular ${ }^{1}$ de la Cátedra de Pediatría de la Universidad Nacional de Córdoba hasta 1955. Sucedió al Dr. José María Valdez.

En 1956, fue fundador ${ }^{2}$ de la Universidad Católica de Córdoba, siendo Rector en ese momento el Padre Jesuita Jorge Camargo.

Fue el primer Decano ${ }^{3}$ de la Facultad de Medicina y el primer profesor titular de la Cátedra de Clínica Pediátrica de la Universidad Católica de Córdoba, hasta que en esta función lo sucedió el Dr. Carlos A. Rezzónico.

Eran tiempos donde la clínica marcaba el rumbo del acto médico, pero lo que marco el espíritu en la formación de la investigación se generó en la Cátedra del Instituto de Fisiología de la Universidad Nacional de Córdoba ${ }^{4}$. Debo contarles aquí, lo que representó ese Instituto en la enseñanza de la medicina de Córdoba y del país, que dejará su impronta en Don Ángel por la investigación. La Cátedra de Fisiología fue creada en la Universidad nacional de Córdoba en 1879, y la enseñanza en los primeros tiempos era esencialmente teórica, luego se sucederían distintos profesores y metodologías de estudio, hasta que en 1935 fue designado profesor el Dr. Oscar Orias, y se inicia un periodo con características especiales. El Dr. Orias formaba parte de la escuela del Prof. Bernando Houssay y

Revista Methodo: Investigación Aplicada a las Ciencias Biológicas. Universidad Católica de Córdoba. Jacinto Ríos 571 Bo Gral. Paz. X5004FXS. Córdoba. Argentina. Tel.: (54) 351 4517299 / Correo: methodo@ucc.edu.ar / Web: methodo.ucc.edu.ar | SEMBLANZAS Methodo 2019;4(4):153-155. 
posteriormente del Dr. Cannoy Wiggre en el extranjero, a decir del De. Agustín Caeiro en su libro "Del hombre y su formación", Orias era un dilecto discípulo de Houssay, él marca una época de la investigación en la enseñanza de la medicina de Córdoba, con él, se inicia la etapa de la medicina científica en Córdoba.

Ángel Segura formó parte de la cátedra y del instituto de Fisiología, y al retirarse el Dr. Orías, Segura asume como titular de la misma en 1946. Esa formación hizo de él la conjunción de un médico con fuerte formación clínica basado en la fisiología. Es por eso que me ha parecido atinado que Ustedes hayan homenajeado al mejor trabajo científico con el nombre del Prof. Dr. Ángel Segura.

No haré mención a su trabajo científico ni a otros cargos por el obtenidos, simplemente a su tesis doctoral denominada "Electrocardiograma en Pediatría".

Pasaré ahora a la segunda parte, que es de algunas de las anécdotas vividas y que muestran parte de su personalidad.

Segura, era un hombre duro, exigentes con el mismo y también con los demás. La primera anécdota que les contaré fue a los pocos meses de haber empezado mi residencia de pediatría en el Hospital de Niño de la Santísima Trinidad de Córdoba en el Servicio de Lactantes Primer Piso del cual el Prof. Segura era su jefe, tercera guardia, sólo con 42 niños, ingresa un lactante séptico, llamó a mi jefe de residentes a las 14 hs, quien me dice: "Está séptico, colócale penicilina más gentamicina e hidrátalo", el niño fue empeorando y fallece cerca de la 7 AM. En las próximas horas, a alguien se le ocurre hacer una punción lumbar a dicho paciente, la cual fue patológica, diagnóstico: meningitis. Unas horas más tarde, en revista de sala, el Dr. Segura, me dice: “Andrés, presente al niño que falleció". Yo sólo, con la mirada de 30 médicos, explico que había hecho, mi diagnóstico de sepsis, sin haber diagnosticado meningitis, aunque había sido tratado como tal, mi cara roja, alguna lágrima seguramente. Termina el ateneo, me llama, solo en su despacho, y me dice: "Andrés, no se cae del caballo el que no anda a caballo", primera enseñanza.

Todos los años repetía: el servicio debe publicar al menos un trabajo por año.

Más adelante, yo ya en segundo o tercer año, presentamos con mi jefe de equipo el primer trabajo en el país sobre alimentación parenteral, el Dr. Segura no me dijo nada. Posteriormente, presentamos el primer trabajo con otro jefe de equipo y otro compañero sobre el uso de fosfomicina en diarrea aguda, al tiempo de publicado, me llamó, yo pensaba que me iba a felicitar, sin embargo, me dijo "se han olvidado de algo, ni siquiera hicieron mención a su jefe, que soy yo".

El Prof. Segura nos dejó una consigna en su hacer "si son clínicos, primero a la asistencia, luego la docencia y luego la investigación, si son investigadores, se invierte dicho orden. No hay docencia sin asistencia".

Para terminar, el uso de la resiliencia, en los años 75 se crea un organismo que evaluaba las residencias del país, cuando evalúan la residencia de la cual era jefe, no fue aprobada. Nos reunió a todos y dijo: "No importa, debemos trabajar más y seguramente lo lograremos". Con el tiempo, sus discípulos creamos una residencia que hoy es de las pocas categorizadas como A por la Comisión Nacional de Evaluación y Acreditación Universitaria (CONEAU).

Formó muchos pediatras previos a la época de las residencias, luego a residentes y posgrados, todos con un gran recuerdo de él.

Para terminar, cuando lo despedimos, se le pidió unas palabras sobre su trayectoria y experiencia, yo he asistido a varias despedidas. Algunos hablan de todos sus logros, títulos y trabajos. Don Ángel dijo solamente: "No hablaré de lo que hice, solo pido perdón por lo que no hice"

Prof. Dr. Andrés A. Gomila

(Discípulo de Don Ángel Segura)

Profesor titular de Pediatría. (1998-2015)

Facultad de Ciencias de la Salud

Universidad Católica de Córdoba 


\section{Bibliografía}

1. González MB. Capítulo 1 Los comienzos. El medio y la gente. En MB González. Una Historia con Sentido. Los primeros 50 años de la Universidad Católica de Córdoba. Córdoba, Argentina: EDUCC Editorial de la Universidad Católica de Córdoba; 2006: 15-50

2. González MB. Autoridades de la Universidad Católica de Córdoba (1956-2006). En MB González. Una Historia con Sentido. Los primeros 50 años de la Universidad Católica de Córdoba. Córdoba, Argentina: EDUCC - Editorial de la Universidad Católica de Córdoba; 2006: 335-344

3. Acerbi Cremades N. Capítulo VII La investigación en la Facultad de Ciencias Médicas. En Acerbi Cremades N.140 años de la fundación de la Facultad de Ciencias Médicas. Córdoba, Argentina: Editorial Universidad Nacional de Córdoba: 2017: 517-554

4. Cairo A. Del Hombre y su Formación. Editorial Talleres Gráficos Biffignandi. Córdoba, Argentina; 1956

$$
\text { (c) (1) Q(9) }
$$

